\title{
Bottle house: Utilising Appreciative Inquiry to develop a user Acceptance model
}

\author{
Arinola Adefila $^{a}$, Amal Abuzeinab ${ }^{\mathrm{b}}$, Timothy Whitehead ${ }^{\mathrm{c}}$, Muyiwa Oyinlola ${ }^{\mathrm{d}}$ \\ ${ }^{a}$ Centre for Global Learning, Education and Attainment, Coventry University, UK, CV1 5FB \\ ${ }^{b}$ Architecture Research Institute, De Montfort University, Leicester, UK, LE1 9BH \\ ${ }^{c}$ School of Engineering and Applied Science, Aston University, Birmingham, UK B4 7ET \\ Institute of Energy and Sustainable Development, De Montfort University, Leicester, UK, LE 1 9BH
}

\begin{abstract}
Purpose (mandatory): This paper develops a novel user-acceptance model for circular solutions to housing design. The model has been systematically developed from a case study of an upcycled plastic bottle building in a low-income community in Nigeria. It is common practice to use participatory approaches to consult end-users in communities, typically after design concepts have been proposed and conceptualised. However, this often leads to critical sociocultural or usability elements being overlooked and the design being substandard. Therefore, this paper develops a robust model for designers, specialists and activists involved in construction that can be used during all phases of a project. This approach demonstrates that user needs should be considered before building designs and plans are generated, providing a greater frame of reference for practitioners, consultants and end-users. Enabling the integration of holistic needs of the community and the development of circular design solution.
\end{abstract}

\section{Practical implications (if applicable):}

Design/methodology/approach (mandatory): A case study methodology has been employed to develop this model, uses appreciative Inquiry methodology. This includes multiple methods to capture end-users perception; focus groups, interactions with the local community, and self-recorded comments. This case study is part of a broader research project to develop replicable low-cost self-sufficient homes utilising local capacity using upcycled, locally available materials.

Findings (mandatory): The findings identify the challenges associated with designing circular-solution housing without a robust understanding of interrelated factors, which ensure sustainability and user acceptance. The conclusions demonstrate why essential sociocultural factors, usually unrelated to technical development, should be understood and contextualised when designing sustainable solutions in Low/Middle-Income Communities. We argue that without this holistic approach, undesirable consequences may arise, often leading to more significant challenges. Instead of referring to multiple frameworks, this distinctive model can be used to evaluate user acceptance for low-cost housing in particular and other dimensions of circular solution design that involve end-user acceptance. The model blends circular solution dimensions with user-acceptance concerns; offering a guide that considers essential features that are both user-friendly and pragmatic; such as utility, technological innovation and functionality as well as their intersectionality.

Research limitations/implications (if applicable): The research relied on a single case study, which focused on end-user engagement of upcycling waste materials as an 
application of circular solutions. The model will contribute to developing socially accepted circular solutions taking into consideration local context factors.

\section{Social implications (if applicable):}

Originality/value (mandatory): The paper is proposing a model for user acceptance of circular construction materials relevant to low and middle-income countries (LMICs).

Keywords: Bottle house, case study, circular solutions, upcycled materials, user acceptance.

\section{Introduction}

\subsection{Background}

The circular economy has become a crucial part of sustainability discourse in recent years and prominent scholars in this field such as (Mathews, Tang and Tan, 2011; Stahel, 2016; Murray, Skene and Haynes, 2017) have called for the adoption of its key principles; reuse and recapture to be incorporated into socioeconomic practices across all sectors. Consequently, the circular economy plays a significant role in the global shift to a more sustainable planet (Preston, 2012).

The construction sector has a reputation for its high environmental footprint (Meyer, 2009) and a significant amount of work has been done to integrate circular economy principles and models into the sector (see Smol et al., 2015; Esa, Halog and Rigamonti, 2017; Ghisellini, Ripa and Ulgiati, 2018). A key part of this is reducing waste and avoiding heavy reliance on landfills. Instead, the value should be added through upcycling of materials to make the current waste streams reusable (Bridgens et al., 2018). In addition to reducing the environmental impact of construction, this approach also has the potential to reduce the cost of building and can educate and empower individuals at the grassroots to become engaged in sustainable practices (Seyfang and Smith, 2007). For example, utilising upcycled material reduces the number of new materials required; which significantly impacts on the cost of the building. In low and middle-income countries (LMICs), it has been identified that labour is relatively inexpensive and materials make up the majority of the construction costs; as such, buildings could become more affordable. Furthermore, using locally upcycled materials can reduce/eliminate transport costs, which can be significant economically and lead to further reductions in overall building costs. It can be argued that upcycling materials has the potential to change both social and economic attitudes to housing and construction.

Several scholars have reported using upcycled materials such as plastic waste (Mansour and Ali, 2015; Mokhtar et al., 2015; Muyen, Barna and Hoque, 2016; Kim et al., 2019) and agricultural waste (Ghavami, 1995; Sales and Lima, 2010; Korjenic et al., 2011) for constructing housing for low-income communities of LMICs. Oyinlola and Whitehead (2019) are among the many who have suggested using suitable, locally sourced materials and resources for developing affordable and sustainable homes. Consequently, there is an opportunity for communities to use locally engineered materials and develop adaptable designs suitable to the needs and ethos of local communities.

Furthermore, many communities in LMICs have a tradition of upcycling materials with strong beliefs and attitudes rooted in religious values around oneness with the earth (Davis, 2016). 
The case for upcycling materials for construction, in these communities, can be further strengthened by the fact that infrastructure for waste management is typically underdeveloped and linked to traditional practices that do not account for current waste streams, such as plastic. Therefore, the new demand for these materials can place a higher premium on these waste streams, which could help incentivise community members to partake in sustainable waste management practices. This approach has broader implications for the development of circular economies as they relate to traditional beliefs and values around development, education, socio-cultural life and economic justice (Ilić and Nikolić, 2016).

Despite the numerous studies on using upcycled materials for constructing homes, none of these has reported on user acceptance. Begum et al., (2009) and Jin et al., (2017) have studied the perception of designers, architects and/or builders on applying circular economy principles in the construction phase, demonstrating the imprudence of ignoring the sociocultural and practical requirements for end-users. Nair et al, 2005 showed that adequate housing differs from individual to individual. Therefore, the materials and design employed should suit the inhabitants' customs and local building traditions. Besides being a physical necessity, housing has inherent cultural, economic and social connotations (Nix et al., 2018). Indeed, housing and the corresponding architecture have constituent identity undertones that could significantly affect the psychological well-being of the occupants. There is little or no understanding in the design process of the perception of end-users of buildings constructed from upcycled materials.

Pomponi and Moncaster, (2017) conducted extensive research which focuses on the built environment and concluded that the role of people, both on an individual level as well as society level, should be the focus of future research and efforts, to accelerate circular economy approaches to construction. An understanding of end users' perceptions are crucial, closing the loop in terms of social sustainability. The advantages of upcycling for construction in LMICs outlined above, make a compelling case for studying the end-users' perception in this context.

\subsection{Bottle House Project}

This paper is part of the Bottle House (see figure 1) project, which is an international, transdisciplinary, collaboration between academia, industry and end-users in a low-income community of Nigeria (Oyinlola et al., 2018). The project explored the design and building of an affordable, sustainable home from upcycled materials; the walls were constructed using plastic bottles, ceiling from used bamboo scaffolding and the floor was created from recycled tiles. This paper reports on the methods and results to evaluate the end user's perception of using upcycled materials. The paper proposes a model for user acceptance testing, which considers quality, functionality, cultural alignment, affordability and community education. 

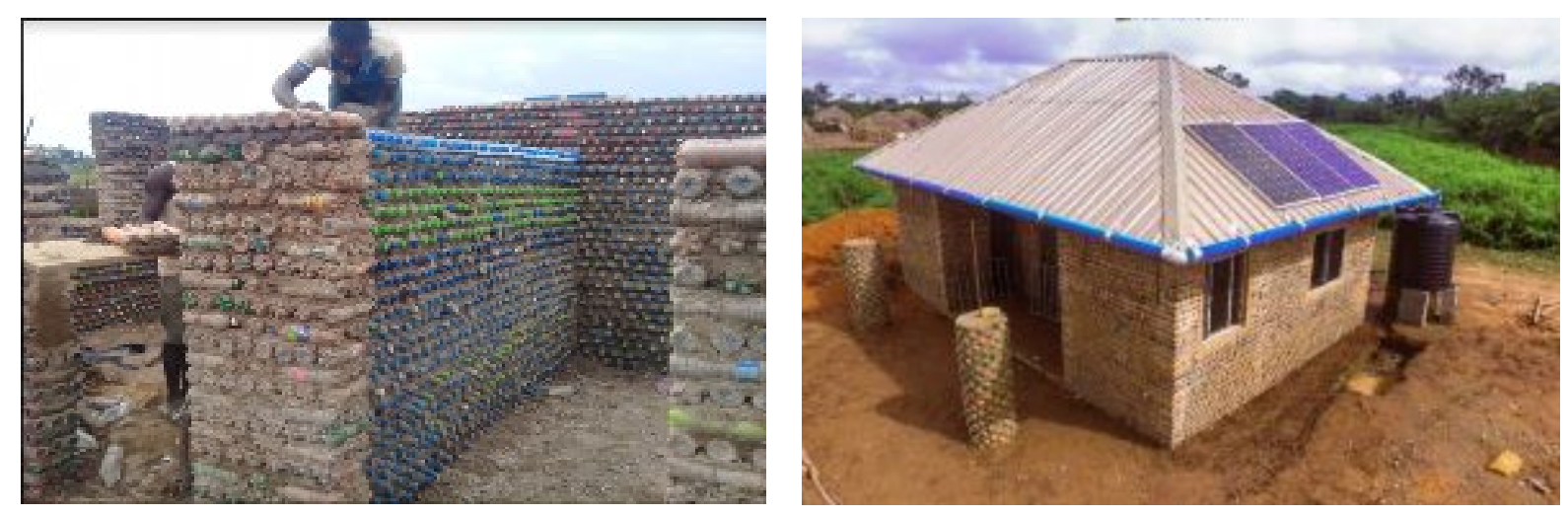

Figure 1: Bottle house in Paipe, Abuja, Nigeria (Oyinlola et al., 2018)

The overarching aim of the project was to develop a low-cost self-sufficient home that can be easily replicated by local capacity using indigenous materials (Oyinlola et al., 2018). The project had several specific objectives including technical, economic and environmental consideration. In this paper, we report on the fourth objective - To investigate the social viability (acceptance) of a low cost, sustainable home, and answer the research question: How is a house, incorporating upcycled materials, perceived among end-users in Nigeria?

The objective was to understand user acceptance within this specific context, and so a case study approach was adopted. According to Yin (2017), a case study examines a contemporary phenomenon within its real-world context, which will allow for a more precious description of the phenomenon. Appreciative Inquiry (AI) methodology was used to explore the various dimensions of the case study. This methodological approach provides scope to interrogate not just the utility of materials for the housing project but also the experiences, drivers and barriers of various elements and practices, critical to the circular solution and associated availability and mechanisms of production. This design was particularly relevant because the project involved a multidisciplinary team with a range of expertise around developing, planning and education for circular solutions.

\section{Technology Acceptance Framework}

\subsection{User Acceptance Model}

To begin, we explored user-acceptance models; and found several frameworks, which holistically examine user acceptance but do not incorporate the design and functionality needed for background intervention. Nevertheless, two (2) user acceptance models were adapted to provide a comprehensive and distinctive model suitable for assessing user acceptance and exploring essential design dimensions needed for innovative circular solution designs. First, the Technology Acceptance Model (TAM) and its variations Venkatesh, Thong and $\mathrm{Xu},(2012,2016)$ were considered. Though TAM focuses on technology acceptance, it has extended utility in health, education and management (Sun et al., 2013; Becker, 2016). The focus on collective acceptance, motivation determinants and practical utility led the team to think about User Acceptance Testing (UAT) frameworks commonly used in software development and testing as well as the adapted 
Unified Acceptance Theory and Use of technology (UATUT) (Van der Heijden, 2004; Bradley, 2009; Ahmad, 2015). These models have developed from research focused on motivation and behaviour of users, for example, the Theory of Reasoned Action (TRA) (Sheppard, Hartwick and Warshaw, 1988) and Theory of Planned Behaviour (TPB) (Ajzen, 1991). Further, both TAM and UATUT have been adapted to suit discipline-specific investigations, see the E-Technology Acceptance Model (ETAM) (Taherdoost, 2018) or the Compatible Unified Theory of Acceptance and Use of Technology (C-UTAUT). Figure 2 illustrates how TAM has been adapted to incorporate new dimensions or determinants.

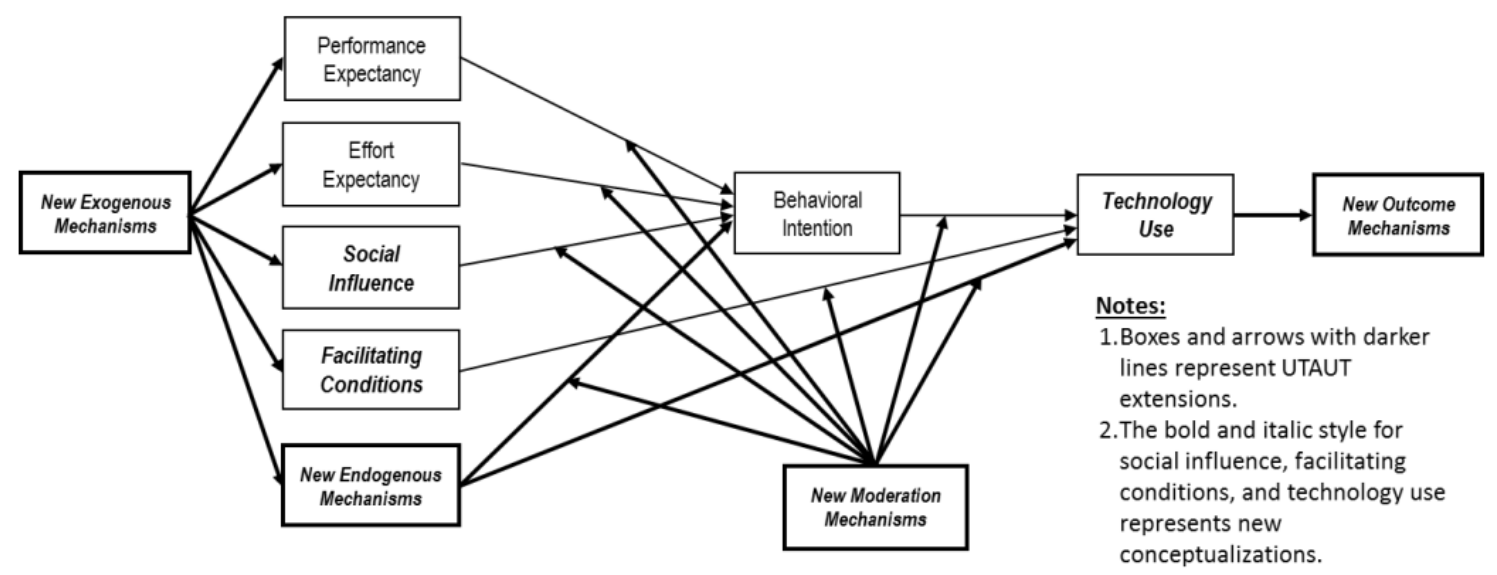

Figure 2: Examples of how UATUT has been adapted (Venkatesh, Thong and Xu, 2016)

Scholars have adopted user acceptance models because they have found the model generally functional but lacking in a specific attribute or feature (Bradley, 2009). For example, software analysis of user acceptance includes elements relating to scalability, data integrity, resilience, security, recoverability. However, these may be broadly understood to be facilitating conditions in a generic UATUT model, in the software industry they are perceptible differences in user acceptance linked to these features.

Venkatesh, Thong and $\mathrm{Xu},(2016)$ introduced an integrated UATUT model (see figure 3) which incorporates a multilayered framework that is effective for this study. The primary attributes are outlined in a meso-layer, sandwiched between specific individual factors at a micro-level and higher contextual feature in a macro layer. Therefore, in this paper, an adapted version of the model for user acceptance is used for testing new technological phenomena in the arena of environmental sustainability, particularly approaches linked to circular economy. 


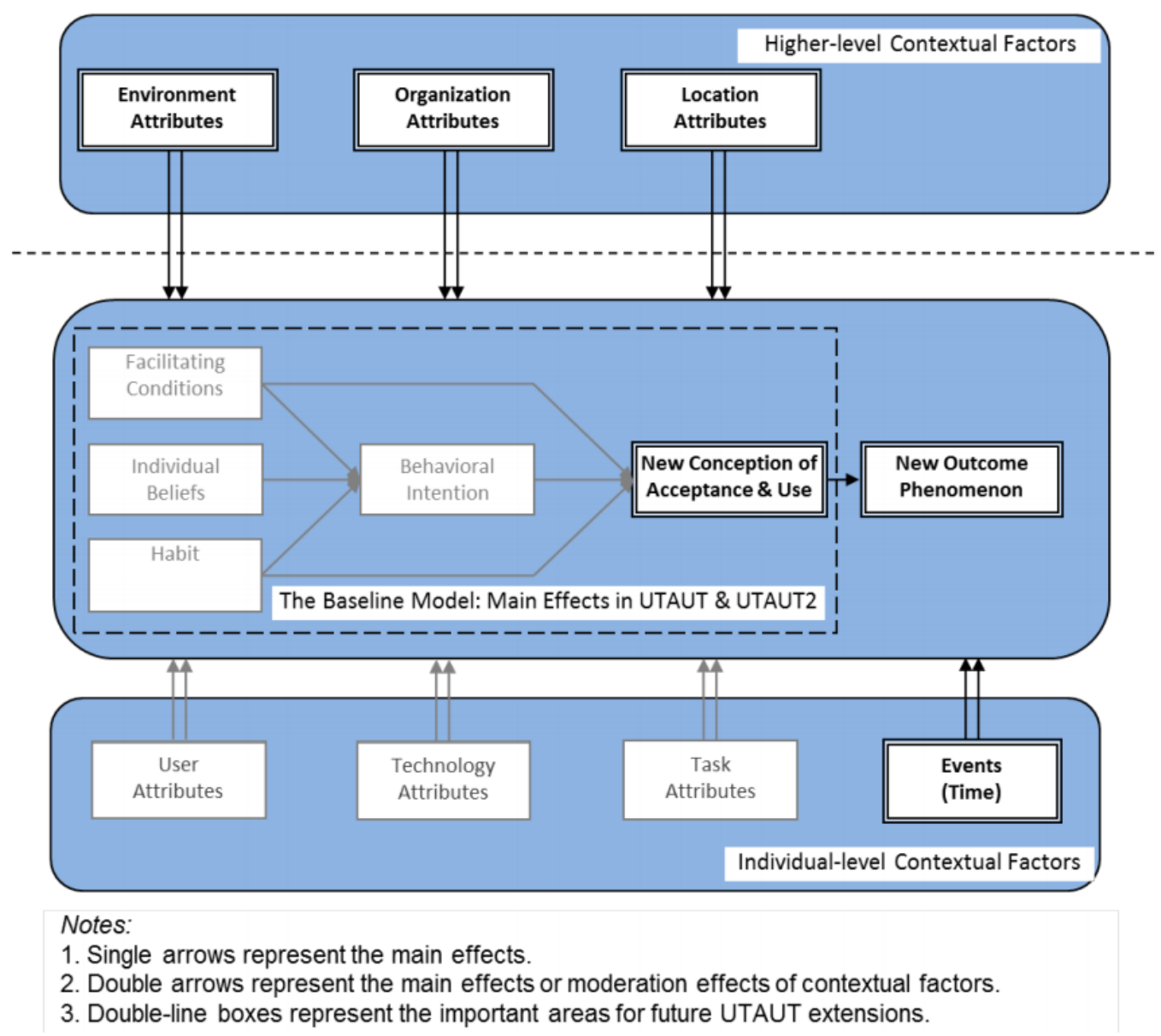

Figure 3: A multi-level Framework of Technology Acceptance and Use (Venkatesh, Thong and $\mathrm{Xu}, 2016)$

\section{Methodology}

\subsection{Appreciative Inquiry (AI)}

AI was used to interrogate the data collated. There are four core principles of AI (Reed 2007):

(a) to identify existing positive aspects of the phenomena,

(b) to explore how the phenomena can be improved, envisioning more desirable outcomes,

(c) co-construct with participants ideal circumstances, prioritising the dimensions that work best

(d) seek ways to implement the change in a sustainable way. Interrogate ways to evaluate and improvise, account for unintended circumstances.

The team were keen to identify all the meaningful insights from the data to integrate multiple dimensions and strands into the proposed acceptance model. The initial phase of the methodology focused on exploring the assets within the community - positive aspects of the circular economy 
used locally in everyday community life, as well as, the positive aspects of construction and building. This appreciation of the particular needs of the case-study population leads to a significant exploration of desirable housing and significant needs - social, economic, political which influenced the design, use and value of buildings in the locality.

The final iterations of the AI methodology took place with researchers from the team exploring coconstructed ideas for the bottle house - the utility of solar panels \& heated water, the possible scope for extensions for rent $\&$ storage of local produce and finally after the bottle house was constructed there were discussions about sustainability and utility. The instruments used to collate data were sequentially aligned to AI methodology and used for all 4 phases - pre-development (identifying assets and exploration of improved outcomes), co-creation and post-development of the bottle house. AI also enabled us to probe and assess the dimensions and attributes of our study that were linked to suitable circular solutions. Especially how practitioners who are involved in designing, building and innovating could perceive these themes. On the other hand, the methodology provided valuable insights from the end-users perspective, as they have to deal with the practical realities of functionality, access and availability of the proposed upcycled materials and continued mechanisms of obtaining and utilising the products if/when they become more valuable.

\subsection{Data collection:}

Using a case study approach and AI methodology, various instruments were used to collect both primary and secondary data. Qualitative methods used included - focus groups, walk and talk interviews as well as comments collated in the logbooks. The primary data from the case study collated data before and after the development of the bottle house. The pre-development stages collated specific primary data related to the case-study participants and the AI methodology implored the researchers to focus data collection on the local assets in the community - which social, political and economic factors influenced building patters and design, any circular methods and indigenous methods already in use, etc. The co-creative element was centrally aligned to themes emanating from the primary data analysis. Secondary data was collated from grey literature, policy documents and local knowledge documented in indigenous narratives, stories and poems.

\subsubsection{Focus Groups}

A focus group can be defined as a group interview intended to exploit a particular group interaction concerning a specified topic or problem (McLafferty, 2004). It is an effective way to gain collective opinion, specifically with respect features which have multi-layered dimensions. Focus groups were used to collate qualitative data; in total, four focus groups were conducted with a variety of stakeholders, as highlighted in the subsequent discussion. Before the commencement of focus group meetings, the research team briefed participants (in English and Hausa - the predominant local language in the region) about the relevance of this stage of the project, discussing the information in the participant information sheet and obtaining relevant consent.

The first two focus groups captured the views of ten households in the community and explored key assests and desirable outcomes for their housing needs. The focus groups were conducted in the local language; a local partner was responsible for the interpretation. The first two focus groups 
were held on two days to ensure maximum participation. In addition, it was noted that the community centre was the most neutral and comfortable location for the focus groups. However, as the community centre was an open plan design, and was therefore difficult to restrict participation to the ten participants in the sample group. Other members from the community participated in the discussions; this contributed to the richness of the data and was viewed as an opportunity to increase interaction and to gain broader insights into local desires and the acceptance of the bottle house in the neighbourhood. The following questions were used to guide the discussion;

What are the most important uses of buildings in the community?

What will you want to have included in your building?

What do you think about plastic bottles as building materials for walls?

Would you consider using plastic bottles to build walls for your house if you were trained?

Focus group one(identifying assets/investigating co-creation) was attended by six households (1 female and 5 males). Four additional members of the community were present, including a local builder, (the local builder was keen to understand the construction technique). The first half of the discussion focused on gathering data around building use, construction design and other positive assets in the community. The second half focused on introducing the potential of the bottle house and co-creating a suitable model for the specific community.

Focus group two (exploring the outcomes) - was attended by four households (1 female and 3 males). The female participant was the same as in focus group 1. Five additional members of the community also participated in the focus group. Once again, the first half involved capturing the assets in the community - positive attributes around building design and utility; local knowledge around reuse of building material and social interactions based on design and rent-for income features.

Focus group three (implementing change) - was conducted at the site of the newly built Bottle House with visitors who were mainly from the local community. It was attended by five participants $(2$ females and 3 males). Those visitors were drawn to the project out of interest, and they wanted to acquire more information from the project team. The data collated focused on attractiveness, utility, negative connotations and non-technical related features - social, cultural and political implications of a bottle house.

Focus group four (implementing change and sustainability) - was conducted at a local developer office. A development officer, who had been recommended as an active practitioner and engages with policymakers in housing matters in Nigeria, convened the meeting. The focus group was attended by 3 practitioners, including the lead developer ( 3 males).

\subsubsection{Walk and talk with the community members:}

A strategic method used in this study was to collate the feedback of people who may not be confident to attend a focus group or do not have the time to devote to a meeting. This aspect involved implementing change and sustainability for circular solutions. The lead researchers positioned themselves next to the three main water boreholes (in the public square) and conducted observations as well as took notes from conversations with locals. The guide questions for this exercise were: 
Have you visited the Bottle House?

What do you think about the Bottle house?

Would you consider living at the Bottle House?

There was always at least one student from the local university to provide translation at the sites. However, most people who approached the researcher in public spaces spoke English. Nineteen members of the local community participated in this exercise.

\subsubsection{Log book for visitors}

This also involved stage 4 of the AI methodology - implementing change and sustainability.

Visitors to Bottle House were able to provide data which was collated via a logbook commissioned at the site. Seventy-one (71) visitors' provided self-record responses over 18 days. The information collated in the logbook included basic demographic data and comments.

\subsection{Data Analysis}

Primary data from the focus groups provided the first iteration of information for co-creation. The data was thematically analysed by three members of the research team with specific expertise in user design analysis and design solutions related to user experience. The themes from the analysis of the first focus groups informed the co-creation phase and the feedback prompts. The data collated for the appreciative cycle involving identifying assets and exploring desirable outcomes were triangulated with secondary data. This provided a quality assurance mechanism that ensured the design and implementation phase were relevant and sustainable. Furthermore, data from secondary sources formed a significant part of the investigation providing the critical contextual dimension. This dimension was important to the technical team and the socio-cultural, political and economic layers that impact the local ebb and flow of daily living and everyday political economy. We interrogated data from the meteorological department around climate and weather patterns, triangulating results from primary sources around average temperature, the direction of sunrays and anomalies in weather patterns. In addition, policy documents and indigenous knowledge were helpful in understanding the local context, culture and aspirations of the people. Particularly with respect to changes around compensation, land use and political participation.

\section{$4 \quad$ Results and discussions}

\subsection{Results from Appreciative Inquiry (AI)}

The technology acceptance frameworks, discussed above, are adapted to support the development of a robust, distinctive user acceptance model for circular solutions for housing design. The team adapted the multi-level framework (Venkatesh, Thong and $\mathrm{Xu}, 2016$ ) which itself is an adaptation of older user acceptance models - TAM, UATUT, etc. This tool has been validated and is based on psychological research around behavioural changes and reasoned action (Sheppard, Hartwick and Warshaw, 1988; Ajzen, 1991).

The case study analysis resulted in a number of key themes, which were examined against the multilevel framework using the AI lens. This provided a scaffold for examining the essential elements 
needed in a user acceptance situation aligned with circular solution principles. The case study data revealed four critical themes relating to the locality:

a. Economic needs - basic facilities developed, rent for income, taking advantage of proximity to the capital, incentives around compensation, transient community, low capital, various sources of income including farming, storage needs for local produce

b. Poor participatory opportunities - lack of agency around political participation concerning compensation, land use or long-term planning

c. Reuse practices - indigenous forms of reuse, sociocultural practices connecting to economic adaptations including use of building space for different purposes, communitarian practices for recycling material, discarding materials that had no relevance to everyday utility

d. Verify and scrutinise - the majority of the participants adopted a "wait and see" attitude. It was difficult to understand why this was prevalent, some indication was provided after the bottle house was built; as participants seemed surprised that the project was completed and included co-creative dimensions. Some participants reported that previous interventions by external agencies typically did not amount to any concrete action.

Using AI the themes were examined along four dimensions for the model development

* What works best? - The essential aspects for end-user acceptance

* Which types of improvements are necessary? What are the envisioned outcomes that could generate better outcomes concerning circular solutions for end-users?

* How can the innovative designs best integrate the priorities and realities of the end-users?

* Who needs to be empowered to deliver the change in a sustainable way for end-users? and Why?

The results are ordered into three dimensions - higher-level contextual dimension, the individual level dimension and the proposed new phenomenon dimension. The thematic analysis from the focus groups, logbooks and walk and talk interviews provided sub-dimensions of the categories. Indicating which key factors concerned the end-users and how various contextual factors intersected with other sometimes seemingly innocuous or benign elements not usually considered. These blind spots could be linked to the policy at a regional level or socio-cultural and historical antecedents which directly or indirectly had a profound interaction with housing and building-related phenomenon.

Analysis from the data showed that broad higher-level contextual factors such as environment and organisation of policy and governance, as well as local context considerations such as user attributes, technology attributes and functionality attributes, are essential factors. Our study identified several critical factors relating to the circular economy that should be considered when developing plans or approaches. It is essential to note that there are many competing demands within host communities and capturing the different web of networked consideration is necessary. Above all, our study shows that it is vital to understand the priorities of the community and how these are weighted in a given 
context; it is equally significant to record associated assumptions, which underpin the stated preferences.

\subsection{Higher-level contextual factors}

In Paipe, it is notable that the community is multicultural; there is a traditional village chief and attending governance structures, who make some political decisions for and on behalf of community members. Nevertheless, everyday political considerations are not entirely regulated by the cultural customs of the indigenous people. A more pragmatic and diplomatic style is used to govern the many new members, many people who live in the area are transient workers.

\subsubsection{Environment attributes}

This is a natural element that will influence the decisions and practice of locals regardless of any intervention. The location is $9.0765^{\circ} \mathrm{N}$ of the equator and $7.3986^{\circ} \mathrm{E}$ of Greenwich Meridian. Rainfall is typically $1389 \mathrm{~mm}$ annually with an average temperature of $25.7 \mathrm{C}$. The area is typical savannah with many shrubs and large sparse vegetation like baobab trees.

There is good arable land for farming, as such the locals want to incorporate their farming practices into the construction cycle. There is copious sunshine for up to 6 months of the year - during the long dry season; this supports building periods with little or no interruptions by thunderstorms or rainfall. The researchers observed how customs linked to environmental attributes will support the use of upcycled, inorganic material like the plastic bottles in our study. The plastics bottles could probably be used in construction throughout the year as they will not be damaged by the rain during the rainy season. However, this may be irrelevant to farmers who will not have the opportunity to engage in building projects during the rainy season.

Inevitably linked to the environment is the local geomorphology and climate. The community used clay that was abundantly available in the community, the local builders had the appropriate skills to manipulate this material and understood its characteristics and malleability. Clay is relatively affordable and comfortable in the hot, arid climate. It can also be made to look atheistically appealing using various design and architectural methods. The local environment and current geomorphological landscape made it possible to access suitable clay deposits easily. It is essential to note the use of clay is perceived to be ecologically sound and technically more aligned to the circular economy. However, there is a predominant perception that clay is not durable and therefore of low quality.

\subsubsection{Organisational attributes:}

Thematic analysis and policy documents showed that local behaviour and architecture were linked to short and medium-term government policy influenced construction. These in turn, demonstrably shaped the organisational attributes in Paipe. The type of building material used in construction is significant in the community because of the compensation schemes related to planning policy and development projects in the local area. Although the community is located in the Federal Capital Territory (FCT) of Nigeria, the settlement is not in the long-term plan of the city. The government is working on land-use schemes and developing amenities retrospectively. When the schemes are fully developed, there are generous compensation packages from the Federal Government. The 
compensations can be significantly higher if building material is more permanent and stable. There is no recognition from the government of stability or structural durability of bottle houses and it is unclear if the planning policy experts will acknowledge upcycled materials. Besides, there is no policy avenue of recognising the value of using upcycled materials that benefit the environment or linking this to climate change action at the local or national level. These broad policy concerns have deep-rooted links to the weak structural deficits in governance across ministries relating to housing, environment, justice, energy/power and planning.

\subsubsection{Location attributes:}

It should be noted that the generous compensation schemes are possible because of the site's relative geographical proximity to the FCT. This geographical advantage has led to high capital costs for land and amenities. In addition, the FCT was created 30 years ago, and the weak infrastructure and institutions of the country have led to many backlogs and bad policy. These have real consequences on building decisions both immediate and retrospectively. The locals, therefore, may not prioritise the circular economy unless the government links compensation schemes to efficient circular economy practices such as the bottle house.

Higher-level contextual factors are often directly linked to the common factors which are beyond the control of the local populace. Environment, geography, geomorphology, government policy and the strength of local community institutions and governance structures shape the agenda and invariably how a circular economy may be adapted for a specific community.

\subsection{Individual contextual factors}

These set of factors involve the agency of individuals in the community. Our project revealed how important individual agency and personal decision making could influence the adoption of circular economy approaches. Individuals can exercise power in many different ways and our analysis revealed a lot of strategic power play taking place at the individual and community level.

\subsubsection{User attributes}

Many locals have weak economic status. They work menial jobs or are engaged in subsistence farming and do not have lots of savings. The reality of their everyday political economy means they cannot make long term decisions about building efficiently. As such, even if a household is knowledgeable about practices that promote the circular economy, it may not have the financial ability to make an individual decision that adapts circular economy solutions Furthermore, individual users have weak political power; they are not directly connected to the influential circles of decision making and policy development. Consequently, they may not be able to take full advantage of the mechanisms that enable them to lobby the government and demand good practice, which benefits them if they adopt circular economy approaches. However, the liaison with development officers in this study proved to be a highly effective strategy for engaging local and federal government officers. This is a critical feature in the model; understanding how the community can sustainably engage with each other, local and federal policy and traditional practices is quite vital. 


\subsubsection{Technology attributes}

During the data collection processes, it was observed that participants were asking questions centred on the durability of the bottle house design, everyone wanted to know how long the house will last. This concern can be related to the fact that most homes in the community are built with local clay and plastered with cement to increase the lifespan and structural stability of the building. The research team explained the testing processes conducted at material labs to ensure that the upcycled material was appropriate for construction. The discussion detailed the selection process and various steps taken into consideration that led to the use of plastic bottles as building material (Oyinlola et al., 2018). Despite the details, participants remained skeptical. This led to a 'wait and see' analysis with several people suggesting they will monitor the durability of the building situated in their community.

\subsubsection{Functionality Attributes}

\subsubsection{Rent-seeking}

Several participants rented rooms to itinerant workers to increase their income. Some participants were concerned that a bottle house may not attract tenants leading to significant loss of income. Exploring the functional and indirect links to using circular approaches is essential in evaluating which materials, designs and models are best suited for LMICs. This will be determined not just by the prevailing economic situation but also by medium-term changes in the wider community; for example, the government plans to develop a low-cost housing scheme in the vicinity, the development of motorways, parks and malls will significantly affect rent prices and even the need to rent much broadly.

\subsubsection{Major incidents/events}

Migrant labour is needed in the Federal Capital Territory; consequently, labourers with little money seek low-income housing temporarily. Major incidents or events - such as international conferences or national occasions in the capital could lead to an influx of temporary workers. Such circumstances make it possible for residents to acquire income - using rooms as "Bed and Breakfast accommodation". These rooms have to be private, secure and have an aesthetic value of varying degrees. Residents can attract more rent from the quality of provision.

In addition, many of the residents do not have the means or economic power to seek planning permits, and this means their houses or additional room may be at risk of demolition if a significant incident such as inspection by the local planning or environmental institutions occurs. It is important to highlight the involvement of local planning authorities, as well as other stakeholders environmental activists, environmental monitoring and regulatory bodies when designing circular economy projects in communities, particularly LMICs where political representation may not be effective because communities have low levels of literacy. Broad participatory level planning is more sustainable, inspires confidence in the upcycled materials and provides a platform to develop policies in government around the utility of the resources locally.

Individual contextual issues are largely determined by local peoples taking personal action. The team observed how collective action is feasible; nevertheless, the capacity to influence change 
remained very individualistic. In Paipe, this could be attributed to the loose governance structure and the multi-cultural nature of the community, and decision making involved convincing individuals directly.

\subsection{New outcomes phenomenon}

Combining the higher contextual and individual contextual elements with broader considerations enabled the team to develop key themes which supported positive outcomes relating to the new approach to the circular economy. The analysis revealed that no single feature was overwhelming when individuals were considering the suitability of the bottle house in particular. When the community members were making decisions they discussed multifactorial elements and the complexity of the situational dynamics. Five major themes relating to how the new aspects of utilising a circular economy approach to design affordable housing were revealed from the findings.

\subsubsection{Facilitating conditions}

Participants considered a range of factors - economic and cultural factors were top highlights in the decision-making process, though these were always juxtaposed among other considerations as discussed above, depending on employment status, individual beliefs and personal decisions, individuals had to make in the short and medium-term.

\subsubsection{Economic considerations}

Though the participants expressed a desire for low-cost building materials, this was countered by the short-term consideration linked to rent-seeking. Majority of the locals rent rooms as a source of additional income. The durability of the building material can attract higher rent. Potential tenants may not be inclined to pay the same rates for rent in the "cheaper" bottle house. This is a crucial feature, which needs to be tested in Paipe.

Most residents were farmers and could use spare rooms to store local produce - yams, cassava, bananas. These are typically stored in specialised clay-built barns which are kept cool by the clay pores and strategically placed holes at the top/bottom of the barns. Though technically, residents could use upcycled materials to develop barns which could also fulfil this function, it was not tested in this study.

\subsubsection{Individual beliefs}

The participants in our study discussed several beliefs that were typically personalised - a desire to have a communal courtyard for socialising could influence decisions around adapting the design features. In addition, participants discussed the concept of the bottle house concerning the amenities - internal toilets, solar panels, having a beautiful, secure home, etc. This shows the importance of using participatory approaches to explore the views of as many individuals as possible before designing housing that uses circular economy approaches, especially in a diverse, multicultural neighbourhood.

\subsubsection{Habit/Familiarity}

Some participants were disconcerted by the nature of the 'waste'. They felt the upcycled materials were waste that will make the houses aesthetically undesirable. This connection could be seen as 
repelling; however, the residents acknowledged that the design of the house, the unique rendering and typical roof make the house look appealing, perhaps even adding a touch of "style". The participants confirmed that though affordability is a vital issue when it comes to housing in the FCT, people were still keen to ensure houses were safe, durable and aesthetically appealing. For example, significant estate development in the FCT used alternative construction methods to speed construction and deliver mass housing. The uptake in this estate was considerably low and development eventually halted. The poor uptake was attributed to people not being familiar with the material. According to the participants, acceptability is a significant issue to overcome when introducing alternative construction methods. The participants also highlighted a key point - "let the unconventional facade appear conventional."

\subsubsection{Behavioural intention:}

Visitors were generally charmed with the idea of using plastic bottles for the wall. The fascination centred on how a common waste material, such as plastic bottles, could be used for construction as well as how the wall appeared externally, making the house look different and beautiful. Participants who admired the house did not feel the upcycled material was repelling. One participant stated: "I came to see this house because people are talking about it and from a distance, it looked beautiful because different colours are appearing from outside." It is worth mentioning that this comment, as well as others in the visitor's logbook, are from people who live outside the community, a majority of these were middle-income earners.

\subsection{User Acceptance Model for Circular solutions in Low-Cost Housing}

The elements above have been translated into a model, Figure 4, that promotes a multidimensional, intersectional approach when engaging with LMICs in similar contexts. This model enables designers to empower the voice of the local community and allows the local agency of the peoples to influence the design process. It includes a 360-degree view of organic elements, such as environmental factors, which drive local practices relating, not just to construction but also the everyday political economy, which forms the fundamental considerations when individuals are deciding to adapt to a new phenomenon. It engages individuals, encourages collective action and includes local stakeholders, both politically and culturally influential people (internal \& external), who influence practice. Most importantly, it is respectful of traditional and individual beliefs, while providing an avenue to ensure the people are aware of the knowledge, skills, technical competencies and broad environmental ideas that the designers are considering. 

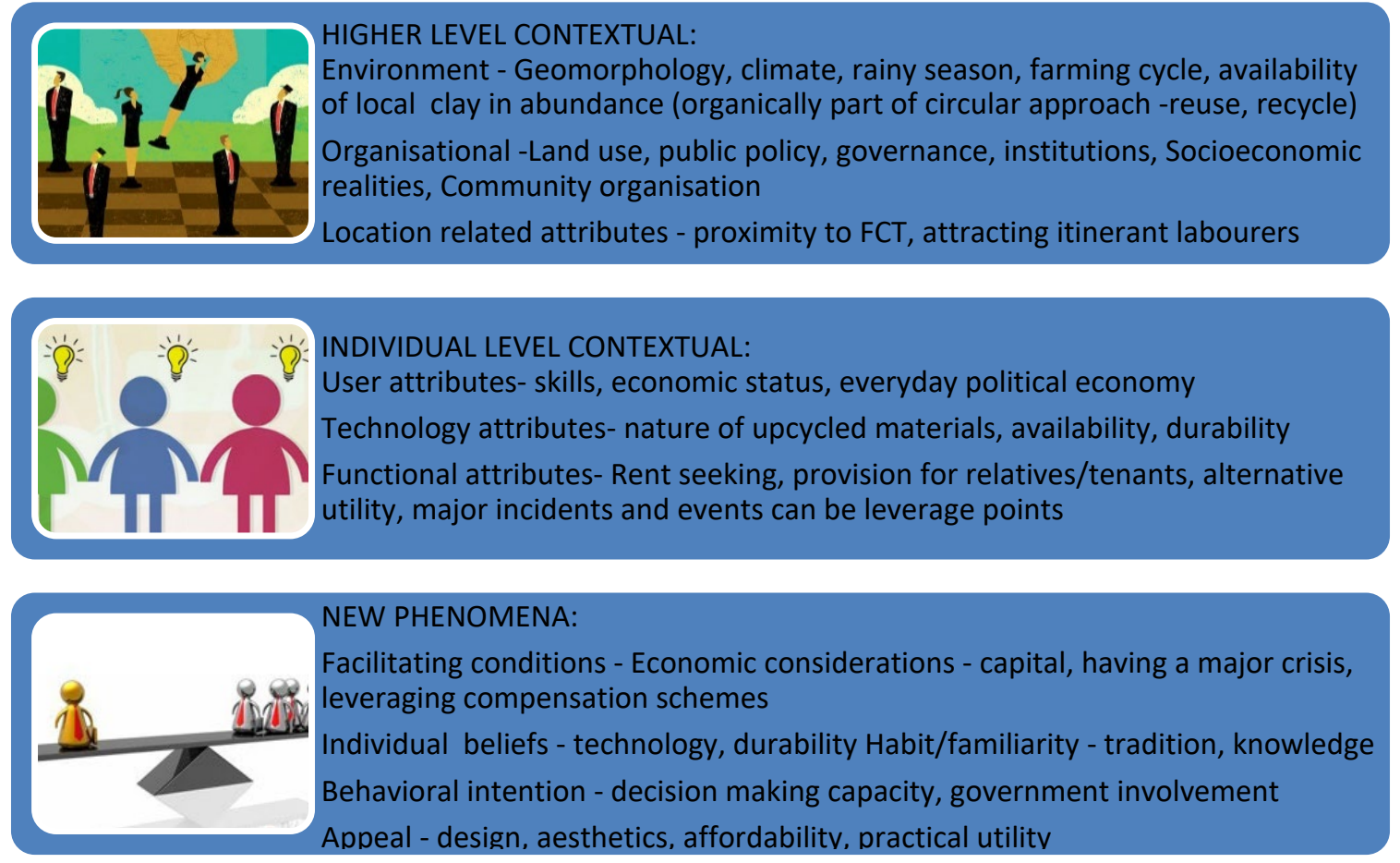

Figure 4: Circular solutions for low-cost housing end-user acceptance model

\subsection{Discussion}

The Circular solutions for low-cost housing end-user acceptance model uses multi-layered factors starting with broad higher-level contextual factors such as environment and organisation of policy and governance to explore how end-users experience circular solutions inspired designs for housing. These factors need to be considered carefully from the outset to align with the aspirations and sociocultural/economic suitability of residents during participatory consultation (Geissdoerfer et al., 2017). There are also local context determinants including user attributes, technology attributes and functionality attributes. The model emphasised the importance of bringing together the multifactorial analysis needed to ensure the outcomes are understood by the residents, local policymakers and the designers (Ranta et al., 2018). As such, several facilitating conditions that should align with broader and local contextual features are suggested in the model. Intersectionality can help designers avoid the pitfall of using materials which have high technical utility but reduced social efficacy (Winans, Kendall and Deng, 2017). Conditions that may have substantial benefits on a broad basis may not be convenient or pragmatic in a local context due to traditional factors such as cost and performance, that squeeze out any technically inherent advantages. Utilising a comprehensive model will enable stakeholders to consider a broad range of factors and reduce the probability of unforeseen and undesirable consequences.

Working closely with the end-user will drive user acceptability, but it is essential to consider compensation and negotiation to arrive at acceptable solutions which may offset traditional preferences for more significant environmental benefits (Pomponi and Moncaster, 2017). The key in this approach is an empowerment that leaves the decision making with the community but provides professional and technical experts with the information and capability to make informed 
decisions, given the local context and the weak capital base of the members of the community (Begum et al., 2009).

This research will impact how stakeholders engage with LMICs when developing solutions with upcycled materials that are technically replicable and socially acceptable. The major limitation of this study is the utilisation of a single case study - restricting the potential to observe features in multiple geographical settings with different local conditions. Nevertheless, the model provides a robust guideline as it draws upon previously validated user acceptance frameworks to establish critical considerations for designing circular economy approaches to housing design for LMICs.

\section{Conclusion}

The circular solutions for low-cost housing end-user acceptance model presented in this paper are developed by analysing data from a single case study research project. The overarching aim was to create a low-cost self-sufficient home that can be replicated by local capacity using upcycled locally available materials in the central region of Nigeria. The specific objective of this paper was to develop a distinctive model that could evaluate the end-users acceptance of upcycled materials in construction, which is an application of circular solutions.

The model was developed by adapting validated technology acceptance frameworks that have been used extensively in various disciplines to evaluate end-user perceived behaviour and potential reaction to new phenomena. By investigating the multiple dimensions and attributes involved in end-user acceptance of circular solutions for low-cost housing, the team were able to identify, envision, prioritise the network of relevant considerations into a systematic and distinctive model for housing-related circular solution design.

The circular solutions for low-cost housing end-user acceptance model includes various attributes including; user, technology and functionality considerations and their intersectionality. This model will help practitioners to gain a robust understanding of interrelated factors, which ensure sustainability and user acceptance as well as to identify the challenges associated with using upcycled materials in construction. It demonstrates why essential sociocultural factors, usually unrelated to technical development, should be understood and contextualised when designing sustainable solutions in Low-Income Communities.

\section{$6 \quad$ Funding}

The project is supported by the Royal Academy of Engineering (FoESF1617 \1\13) through the Frontiers of Engineering for Development seed corn funding in 2016.

\section{References}

Ahmad, M. I. (2015) 'Unified theory of acceptance and use of technology (UTAUT)', LinkedIn Pulse.

Ajzen, I. (1991) 'The theory of planned behavior', Organizational Behavior and Human Decision 
Processes. Academic Press, 50(2), pp. 179-211. doi: 10.1016/0749-5978(91)90020-T.

Becker, D. (2016) 'Acceptance of Mobile Mental Health Treatment Applications', Procedia Computer Science. Elsevier, 98, pp. 220-227. doi: 10.1016/J.PROCS.2016.09.036.

Begum, R. A. et al. (2009) 'Attitude and behavioral factors in waste management in the construction industry of Malaysia', Resources, Conservation and Recycling. Elsevier, 53(6), pp. 321-328. doi: 10.1016/J.RESCONREC.2009.01.005.

Bradley, J. (2009) 'The technology acceptance model and other user acceptance theories', in Handbook of research on contemporary theoretical models in information systems. IGI Global, pp. 277-294.

Bridgens, B. et al. (2018) 'Creative upcycling: Reconnecting people, materials and place through making', Journal of Cleaner Production. Elsevier, 189, pp. 145-154. doi:

10.1016/J.JCLEPRO.2018.03.317.

Davis, D. K. (2016) The arid lands: history, power, knowledge. MIT Press.

Esa, M. R., Halog, A. and Rigamonti, L. (2017) 'Developing strategies for managing construction and demolition wastes in Malaysia based on the concept of circular economy', Journal of Material Cycles and Waste Management. Springer Japan, 19(3), pp. 1144-1154. doi: 10.1007/s10163-0160516-x.

Geissdoerfer, M. et al. (2017) 'The Circular Economy - A new sustainability paradigm?', Journal of Cleaner Production. Elsevier, 143, pp. 757-768. doi: 10.1016/J.JCLEPRO.2016.12.048.

Ghavami, K. (1995) 'Ultimate load behaviour of bamboo-reinforced lightweight concrete beams', Cement and Concrete Composites, 17(4), pp. 281-288. Doi: //doi.org/10.1016/0958-9465 (95)00018-8.

Ghisellini, P., Ripa, M. and Ulgiati, S. (2018) 'Exploring environmental and economic costs and benefits of a circular economy approach to the construction and demolition sector. A literature review', Journal of Cleaner Production. Elsevier, 178, pp. 618-643. doi: 10.1016/J.JCLEPRO.2017.11.207.

Van der Heijden, H. (2004) 'User acceptance of hedonic information systems', MIS quarterly. JSTOR, pp. 695-704.

Ilić, M. and Nikolić, M. (2016) 'Drivers for development of circular economy - A case study of Serbia', Habitat International, 56, pp. 191-200. doi://doi.org/10.1016/j.habitatint.2016.06.003.

Jin, R. et al. (2017) 'An empirical study of perceptions towards construction and demolition waste recycling and reuse in China', Resources, Conservation and Recycling. Elsevier, 126, pp. 86-98. doi: 10.1016/J.RESCONREC.2017.07.034.

Kim, B. et al. (2019) 'Behaviour of sand-filled plastic bottled clay panels for sustainable homes', Journal of Building Engineering, p. 100895. doi: 10.1016/j.jobe.2019.100895.

Korjenic, A. et al. (2011) 'Development and performance evaluation of natural thermal-insulation materials composed of renewable resources', Energy and Buildings, 43(9), pp. 2518-2523. doi: //doi.org/10.1016/j.enbuild.2011.06.012. 
Mansour, A. M. H. and Ali, S. A. (2015) 'Reusing waste plastic bottles as an alternative sustainable building material', Energy for Sustainable Development, pp. 79-85. doi:

//doi.org/10.1016/j.esd.2014.11.001.

Mathews, J. A., Tang, Y. and Tan, H. (2011) 'China's move to a Circular Economy as a development strategy', Asian Business \& Management. Palgrave Macmillan UK, 10(4), pp. 463484. doi: 10.1057/abm.2011.18.

McLafferty, I. (2004) 'Focus group interviews as a data collecting strategy', Journal of advanced nursing. Wiley Online Library, 48(2), pp. 187-194.

Meyer, C. (2009) 'The greening of the concrete industry', Cement and Concrete Composites. Elsevier, 31(8), pp. 601-605. doi: 10.1016/J.CEMCONCOMP.2008.12.010.

Mokhtar, M. et al. (2015) 'Application of plastic bottle as a wall structure for green house', $A R P N$ Journal of Engineering and Applied Sciences.

Murray, A., Skene, K. and Haynes, K. (2017) 'The Circular Economy: An Interdisciplinary Exploration of the Concept and Application in a Global Context', Journal of Business Ethics. Springer Netherlands, 140(3), pp. 369-380. doi: 10.1007/s10551-015-2693-2.

Muyen, Z., Barna, T. N. and Hoque, M. N. (2016) 'Strength properties of plastic bottle bricks and their suitability as construction materials in Bangladesh', Progressive Agriculture, 27(3), pp. 362368.

Nair, D. G. et al. (2005) 'A conceptual Framework for sustainable-affordable housing for the rural poor in less developed economies', in Proceedings. The 2005 World Sustainable Building Conference, Tokyo, 27-29 September 2005 (SB05Tokyo).

Nix, E. et al. (2018) 'Participatory Action Research as a Framework for Transdisciplinary Collaboration: A Pilot Study on Healthy, Sustainable, Low-Income Housing in Delhi, India', Global Challenges, p. 1800054.

Oyinlola, M. et al. (2018) 'Bottle house: A case study of transdisciplinary research for tackling global challenges’, Habitat International, 79, pp. 18-29. doi: 10.1016/j.habitatint.2018.07.007.

Oyinlola, M. and Whitehead, T. (2019) 'Recycling of Plastics for Low Cost Construction', Reference Module in Materials Science and Materials Engineering. Elsevier. doi: 10.1016/B9780-12-803581-8.11523-1.

Pomponi, F. and Moncaster, A. (2017) 'Circular economy for the built environment: A research framework', Journal of Cleaner Production. Elsevier, 143, pp. 710-718. doi: 10.1016/J.JCLEPRO.2016.12.055.

Preston, F. (2012) A Global Redesign?: Shaping the Circular Economy. Chatham House London.

Ranta, V. et al. (2018) 'Exploring institutional drivers and barriers of the circular economy: A cross-regional comparison of China, the US, and Europe', Resources, Conservation and Recycling. Elsevier, 135, pp. 70-82. doi: 10.1016/J.RESCONREC.2017.08.017.

Reed, J. (2007). Appreciative inquiry: Research for change. Thousand Oaks, CA: Sage. 
Sales, A. and Lima, S. A. (2010) 'Use of Brazilian sugarcane bagasse ash in concrete as sand replacement', Waste Management, 30(6), pp. 1114-1122. doi:

//doi.org/10.1016/j.wasman.2010.01.026.

Seyfang, G. and Smith, A. (2007) 'Grassroots innovations for sustainable development: Towards a new research and policy agenda', Environmental Politics. Routledge, 16(4), pp. 584-603. doi: 10.1080/09644010701419121.

Sheppard, B. H., Hartwick, J. and Warshaw, P. R. (1988) 'The theory of reasoned action: A metaanalysis of past research with recommendations for modifications and future research', Journal of consumer research. The University of Chicago Press, 15(3), pp. 325-343.

Smol, M. et al. (2015) 'The possible use of sewage sludge ash (SSA) in the construction industry as a way towards a circular economy', Journal of Cleaner Production. Elsevier, 95, pp. 45-54. doi: 10.1016/J.JCLEPRO.2015.02.051.

Stahel, W. R. (2016) 'The circular economy', Nature, 531(7595), pp. 435-438. doi: $10.1038 / 531435 \mathrm{a}$.

Sun, Y. et al. (2013) 'Understanding the acceptance of mobile health services: a comparison and integration of alternative models', Journal of Electronic Commerce Research. Journal of Electronic Commerce Research, 14(2), p. 183.

Taherdoost, H. (2018) 'Development of an adoption model to assess user acceptance of e-service technology: E-Service Technology Acceptance Model', Behaviour \& Information Technology. Taylor \& Francis, 37(2), pp. 173-197.

Venkatesh, V., Thong, J. Y. L. and Xu, X. (2012) 'Consumer acceptance and use of information technology: extending the unified theory of acceptance and use of technology', MIS quarterly, $36(1)$, pp. 157-178.

Venkatesh, V., Thong, J. Y. L. and Xu, X. (2016) 'Unified theory of acceptance and use of technology: A synthesis and the road ahead', Journal of the Association for Information Systems, 17(5), pp. 328-376.

Winans, K., Kendall, A. and Deng, H. (2017) 'The history and current applications of the circular economy concept', Renewable and Sustainable Energy Reviews. Pergamon, 68, pp. 825-833. doi: 10.1016/J.RSER.2016.09.123. 